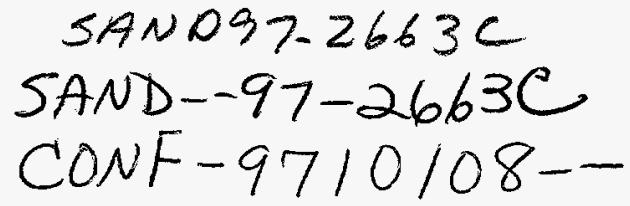

\title{
CHARACTERIZATION OF ENERGETIC MATERIALS AT TEMPERATURES APPROACHING COOKOFF
}

\author{
A. M. Renlund, J. C. Miller, W. M. Trott, K. L. Erickson, and M. L. Hobbs \\ Sandia National Laboratories* \\ Albuquerque, NM 87185
}

$\cdots$

\begin{abstract}
Abstract

We conducted experiments that monitored the response of heated, confined energetic materials in both fixed-volume and fixed-load configurations. We studied a variety of HMXbased materials, looking at the effects of particle size and binders. The $\beta-\delta$ phase transition near $170^{\circ} \mathrm{C}$ led to a more reactive state. Materials that underwent complete transition in the fixed-load experiments (allowed to expand fully to accommodate the $5 \%$ volume increase) cooked off faster than those in the fixed-volume configuration.
\end{abstract}

\section{INTRODUCTION}

An understanding of the state of energetic materials (EMs) at the point of cookoff, or thermal runaway, is necessary to predict the violence of the cookoff reaction. Specifically, the chemical and morphological makeup of the material at the time of ignition controls the subsequent burn dynamics and potential deflagration to detonation transition (DDT). We are approaching this characterization of the thermally degraded material using a small-scale experiment we call the hot cell. $[1,2]$ This experiment was not intended to be a cookoff test, but was designed to allow acquisition of some real-time temperature and pressure measurements so we could understand what the material may look like as it approaches ignition. The experiment also allows for postmortem analysis of the degraded material. In its initial configuration, the hot cell was a fixed-volume experiment. Forces generated within the confined volume due to material expansion, phase transitions or gas generation were measured with a load cell. Only minimal expansion of the cell occurred, primarily due to minor thermal expansion of the cell and bolts, and to load cell response. After calibrating the hot cell response using various inert materials, we studied several EMs and observed characteristic responses for each material. The results showed complex coupling or the mechanical and chemical response of the materials, and the effects were not obviously separable. To date, we focused most of our attention on HMX and HMX-based EMs, and initial results were presented in a previous paper [1]. Recently, we looked at the role of $\mathrm{HMX}$ particle size as well as various formulations, including PBX 9501, PBX 9404 and LX-14. Results of these experiments are presented. To address the complex coupling of the mechanical and chemical response we modified the hot cell to facilitate experiments in a fixed-load configuration that allowed the EM to expand or contract against a movable piston while measuring the piston displacement. In actual use not all EMs are confined in fixed-volume geometries; these new experiments can address cookoff for those classes of components and weapon designs having a fixed or approximately fixed load.

\footnotetext{
-Sandia is a multiprogram laboratory operated by Sandia Corporation, a Lockheed Martin Company, for the United States Department of Energy under Contract DE-ACO4-94AL85000.
}

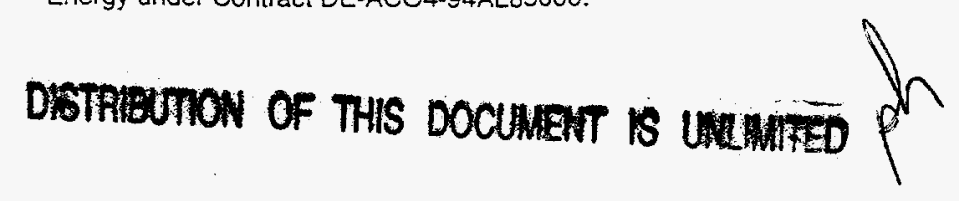




\section{DISCLAMMER}

Portions of this document may be illegible in electronic image products. Images are produced from the best available original document. 


\section{DISCLAIMER}

This report was prepared as an account of work sponsored by an agency of the United States Government. Neither the United States Government nor any agency thereof, nor any of their employees, makes any warranty, express or implied, or assumes any legal liability or responsibility for the accuracy, completeness, or usefulness of any information, apparatus, product, or process disclosed, or represents that its use would not infringe privately owned rights. Reference herein to any specific commercial product, process, or service by trade name, trademark, manufacturer, or otherwise does not necessarily constitute or imply its endorsement, recommendation, or favoring by the United States Government or any agency thereof. The views and opinions of authors expressed herein do not necessarily state or reflect those of the United States Government or any agency thereof. 


\section{EXPERIMENTAL}

The constant-volume hot cell experiment was described previously. $[1,2]$ Both experimental configurations are shown schematically in Figs. 1 and 2. They were built similarly using the same sample size, cell size, heaters and thermocouples. The EM pellet (typically $6.35 \mathrm{~mm}$ diameter by $3.17 \mathrm{~mm}$ thick, $<200 \mathrm{mg}$ ) was confined in a cylindrical cell and on the top and bottom with o-ring-sealed pistons. The top piston on the constant-volume hot cell was fixed. During assembly the system was pre-loaded to several hundred pounds force using a torque wrench. In the constant-load hot cell, the top piston was designed to move up to $\pm 5 \mathrm{~mm}$ with a constant force supplied by a pneumatic cylinder with loading pressures up to $100 \mathrm{lb}$. The bottom piston was threaded into a load cell and the top piston usually contained a thermocouple to measure the surface temperature of the energetic material. The cell was heated with a band heater and cell temperatures were measured with thermocouples. The experiment was conducted with the assembly inside a vacuum chamber and with the valve to the pump nearly closed; thus we could detect any significant leak from the cell without interference from slow outgassing from the heated assembly itself. After heating, samples were extracted to allow postmortem examination for both chemical decomposition and morphology changes.

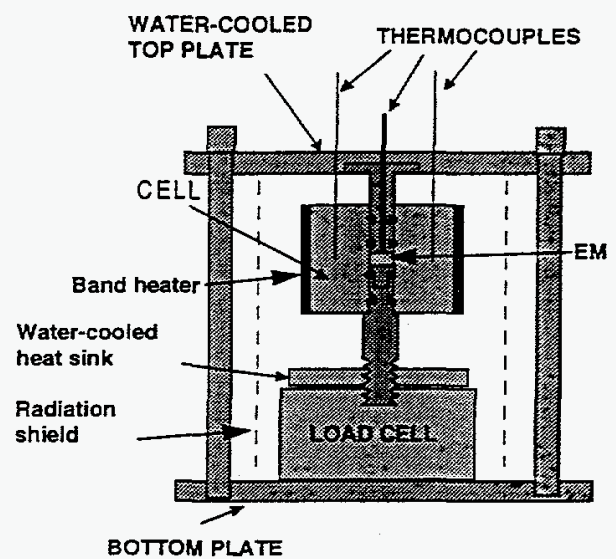

Fig. 1. Schematic of experimental assembly for constant-volume heating.

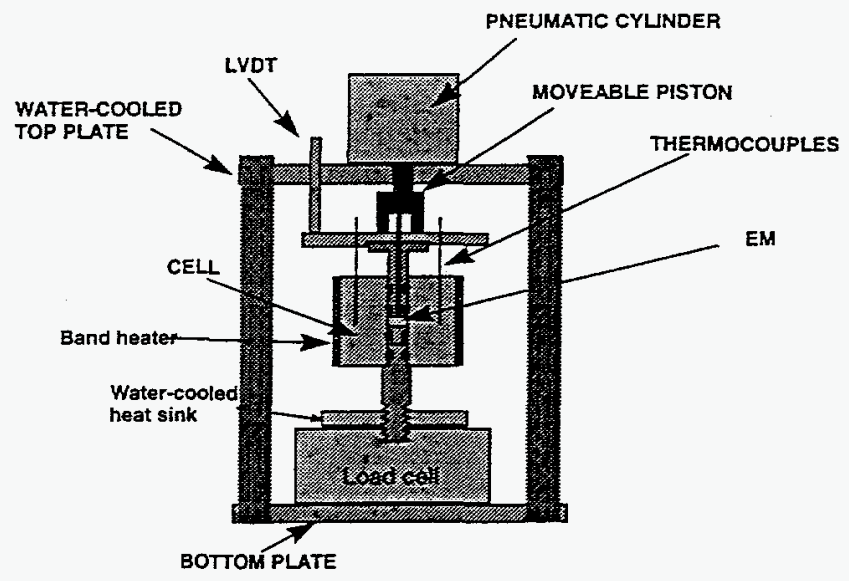

Fig. 2. Schematic of experimental assembly for constant-load heating.

\section{RESULTS}

Preliminary experimental results of constant-volume hot cell experiments on HMX were reported previously.[1] Typical results from such tests are shown in Fig. 3 for an HMX pellet pressed from Holston-grade powder. Three traces are shown for temperature. The thermocouple in contact with the pellet surface always registered the lowest temperature of the three because of the active cooling along the axis. The pressure reading from the vacuum gauge showed a gradual decrease (the vacuum chamber was being slowly evacuated to avoid signal from outgassing) until the o-rings ruptured (just before 100 minutes in Fig. 3). The rapid increase in force near 60 minutes was due to the $\beta-\delta H M X$ phase transition. The decreases 
both before and after the peak were not due to leaks from the cell but rather to some mechanical response of the HMX.

Work by others indicates that the phase transition in HMX may be particle-size dependent.[3] HMX powders that had been sieved for narrow particle size distributions were obtained from Los Alamos National Laboratory. Figure 4 shows the results of constant-volume hot cell experiments on pressed pellets ( 1.78 $\mathrm{g} \mathrm{cm}^{-3}$ ) from two such powder lots: fine, pressed from HMX with $<20 \mu \mathrm{m}$ diameter crystals; and coarse, pressed from HMX with $250-300 \mu \mathrm{m}$ diameter crystals. It is expected that during pressing the coarse particles may have fractured. Results were reproducible, with the fine HMX showing a large decrease in measured load just before the phase transition. To some extent this result is counterintuitive because the fine HMX had more neighboring particles and the force should have been averaged and less prone to change. The observed result indicates some particle rearrangement or packing occurred for fine-particle HMX. The behavior of the HMX following the phase transition always indicated slightly longer reaction times for coarse HMX.

The effects of binders and additives are shown in Fig. 5 which gives results for PBX 9404 (94\% HMX, 3\% NC, $3 \%$ CEF, $0.1 \%$ DPA) and $L X-14$ (95\% HMX, 5\% estane). We are not able to account for the specific differences in the responses of the two materials. Both experiments had o-ring failures and pressure venting. It is important to note that for the PBX 9404 a cookoff event (the temperature spike near 110 minutes)

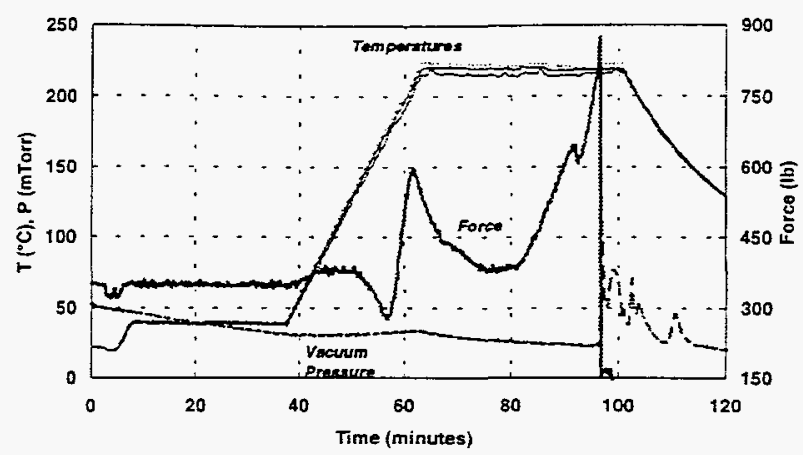

Fig. 3. Results from a constant-volume hot cell experiment for HMX showing temperatures (from 3 thermocouples), force (from load cell) and vacuum chamber pressure.

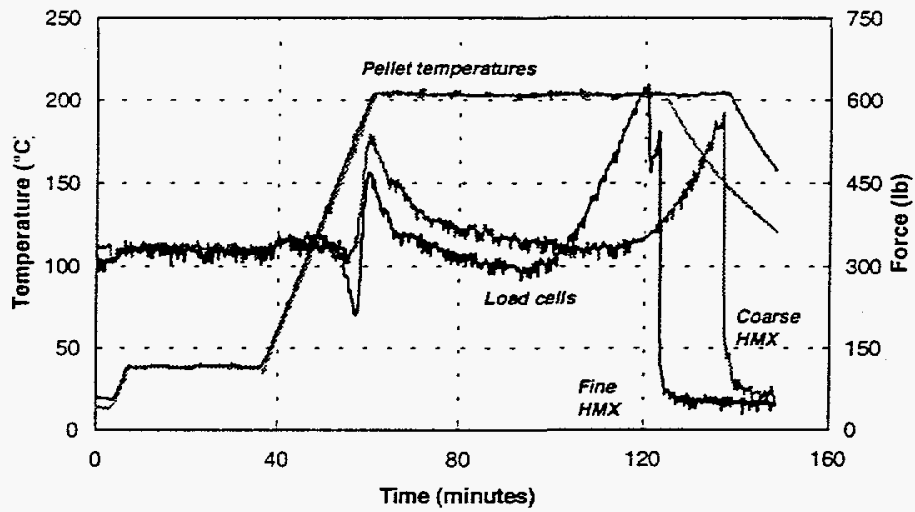

Fig. 4. Results of two constant-volume hot cell experiments on pellets pressed from fine $(-20 \mu \mathrm{m})$ and coarse ( $250 \mu \mathrm{m}) \mathrm{HMX}$.

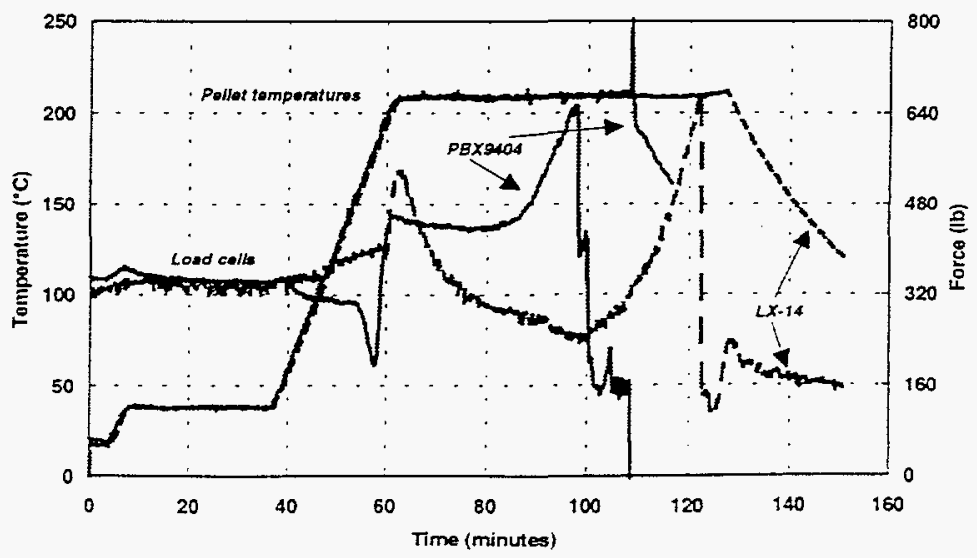

Fig. 5. Constant-volume hot cell results on PBX 9404 and LX-14. 
occurred even after the cell had vented. That event was sufficiently violent to damage the hot cell, the pistons and the load cell.

The constant-load hot cell was designed to provide additional data that might help unravel the complex coupling between chemical and mechanical responses of the energetic materials during confined heating. Starting conditions were different only in the amount of pre-load on the EM: up to $100 \mathrm{lb}$ force for the constant-load experiments, and $300 \mathrm{lb}$ force for the constant-volume experiments. Once heating began, however, the EM in the constant-force experiments was allowed to expand or contract by pushing against a piston. Gas products were sealed using o-rings and the experiment was again conducted under vacuum to observe any leaks from the cell. Both force and displacement data were obtained in these experiments.

Figure 6 shows results from an experiment on $\mathrm{HMX}$. The movable piston contained the thermocouple and it may have had difficulty tracking the pellet temperature as the pellet began to expand rapidly. The first major displacement (near 30 minutes) coincided with the HMX phase transition, and resulted in a $5 \%$ volume change, agreeing with a complete transition to the $\delta$ polymorph. [4] The subsequent rapid displacement accounted for an $80 \%$ increase in volume. The experiment ended just minutes after the rapid expansion began due to a violent cookoff (at 42 minutes in Fig. 6). Load cell, confinement cell, pistons, and the pneumatic cylinder were all damaged. The experiment was repeated with a similar heating history but in a less instrumented form (no pellet thermocouple, no load cell) and the HMX cooked off within 1 minute of the time of the previous test.

Figure 7 shows a comparison of heating experiments performed on $\mathrm{HMX}$ in constant-volume and constant-force configurations. The final temperature was the same in both experiments $(12$ ${ }^{\circ} \mathrm{C}$ below the temperature of the experiment shown in Fig. 6). Clearly there is a substantial difference in the time to significant decomposition reaction indicated by rapid increase in

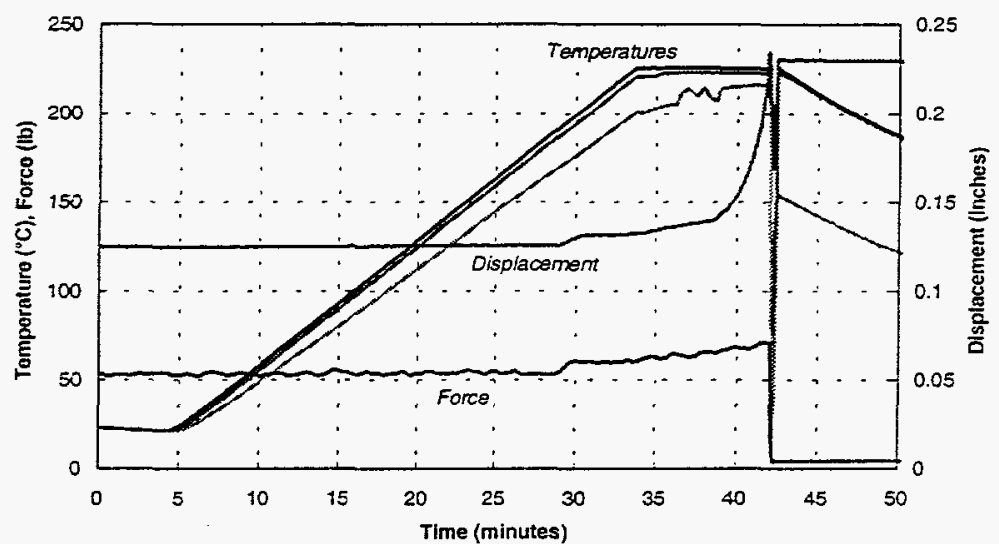

Fig. 6. Response of HMX heated in a constant-load configuration. 
force (for the constant-volume experiment) or displacement (for the constant-load experiment). The final outcomes of the tests were also vastly different. The constant-volume experiment ended with o-ring rupture due to the decomposition gas build-up, which was a relatively mild event that did not damage any of the fixtures. The constant-load experiment ended in a damaging cookoff.

The effect of binder in these cookoff-prone constant-load experiments is shown in Fig. 8 which compares results for $\mathrm{HMX}$ at $1.79 \mathrm{~g} \mathrm{~cm}^{-3}$ and $\mathrm{LX}-14$ at $1.83 \mathrm{~g}$ $\mathrm{cm}^{-3}$. The displacements due to both the phase transition and to the rapid decomposition are subtly different. Clearly the LX-14 reacted slower. The results, however, were similar in that the LX-14 also cooked off with damaging results.

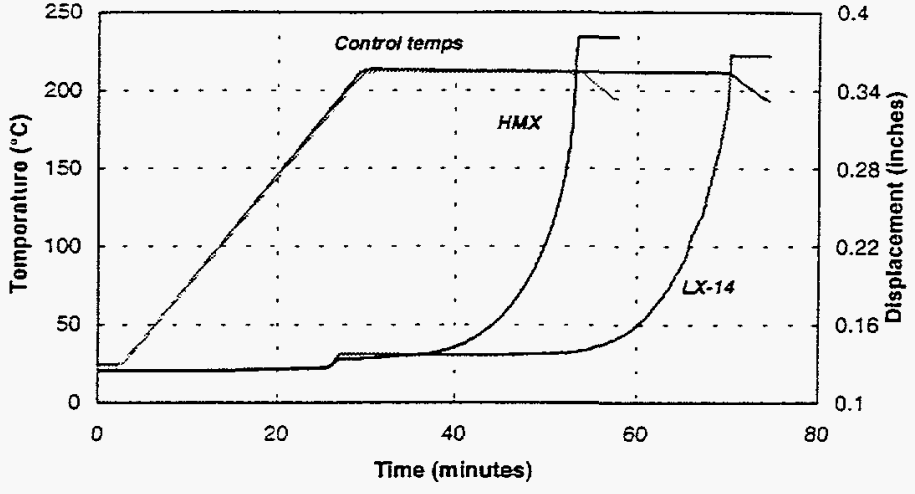

Fig. 8 Comparison of response of $H M X$ and $L X-14$ to heating in constant-load experiment.

\section{DISCUSSION}

We have not yet fully addressed the role of particle size in the mechanical behavior and reactivity of HMX. The response of Holston-grade HMX, which is bimodal in particle size distributions, shown in Fig. 3, seems to be an averaged response of the fine and coarse particle size results shown in Fig. 4. Since the indication of reactivity is the increase in pressure, the longer reaction time observed for the coarse HMX is probably a result of longer times associated with diffusion of decomposition gases out of the larger particles.

It became obvious during these studies that fundamentally different processes occur in the two configurations. Specifically, we focused on the nature of the $\beta-\delta$ phase transition. $\beta-H M X$ has a density of $1.9 \mathrm{~g} \mathrm{~cm}^{-3}$ while $\delta-H M X$ has a lower density of $1.8 \mathrm{~g} \mathrm{~cm}^{-3}$.[4] The rapid increase in force measured in the constant-volume experiments at the phase-transition temperature is clear evidence of this increased crystal volume. However, it is not clear how much expansion, and therefore what percentage of $H M X$ conversion, can be accommodated. One explanation of the relaxation observed after the initial pressure increase is that it may be due to conversion of the HMX back to the $\beta$-phase. Lacking any direct experimental evidence of how much HMX may have converted to $\delta$, we used modeling tools to obtain estimates.

A preliminary hydrostatic stress-strain constitutive model for decomposing energetic materials under various loading conditions has been developed previously.[5,6] This Reactive ElasticPlastic (REP) constitutive model is founded on the collapse and growth of internal inclusions resulting from physical and chemical processes such as forced displacement (preloading), thermal expansion, and/or decomposition. Stress is determined for any change in strain, temperature, and/or fraction of solid converted to gas. The REP constitutive model does not currently consider the effect of phase change. The REP model was used to model the constant-volume hot cell experiment. 
Figure 9 shows the load cell force for HMX to which the model was compared. The HMX pellet at $20^{\circ} \mathrm{C}$ ramped to about $40^{\circ} \mathrm{C}$ within 5 minutes. The pellet temperature was then held at about $40^{\circ} \mathrm{C}$ for 30 minutes. The pellet temperature was then ramped at approximately $7^{\circ} \mathrm{C} / \mathrm{min}$ to $195^{\circ} \mathrm{C}$. The pellet temperature was held at $195^{\circ} \mathrm{C}$ for about an hour. The pellet had an initial preload of about $400 \mathrm{lbf}$.

The HMX hot cell data showed variations in axial force, due to thermal expansion, particle packing, phase change, and gas formation. At approximately 35 minutes, the force started to increase due to thermal expansion of the invar rods. Between 46 and 56 minutes $\left(108^{\circ} \mathrm{C}\right.$ and $\left.172^{\circ} \mathrm{C}\right)$, the measured force decreased.

At low pressure, two solid-to-solid phase changes in HMX occur at $102-104^{\circ} \mathrm{C}(\beta-\mathrm{HMX}$ to $\alpha-$ $H M X)$ and $160-164^{\circ} \mathrm{C}(\beta-H M X$ to $\delta-H M X)$. The force increase between 56 minutes and 60 minutes $\left(172^{\circ} \mathrm{C}\right.$ and $\left.192^{\circ} \mathrm{C}\right)$ was likely due to the formation of $\delta$-HMX. The conversion of $\beta$ $H M X$ (or perhaps $\alpha-H M X$ ) to $\delta-H M X$ between 54 and 60 minutes in Fig. 9 is probably not complete. To model the force relaxation between 46 and 56 minutes and the force increase between 56 minutes and 60 minutes, the HMX pellet displacement was prescribed. The relaxation between 46 and 56 minutes was prescribed by decreasing the HMX pellet height by $0.005 \mathrm{~cm}$. The force increase between 56 and 60 minutes was obtained by increasing the HMX pellet height by $0.005 \mathrm{~cm}$. The prediction with the prescribed displacements is shown in Fig. 9 as the line labeled $30 \% \beta-H M X$. The $0.005 \mathrm{~cm}$ change between 56 and 60 minutes is attributed to the solid-to-solid conversion of $\beta-H M X\left(\rho=1.9 \mathrm{~g} \mathrm{~cm}^{-3}\right)$ to $\delta-H M X\left(\rho=1.8 \mathrm{~g} \mathrm{~cm}^{-3}\right)$. An increase in pellet height from $3.175 \mathrm{~mm}$ to $3.225 \mathrm{~mm}$ would cause the density to decrease from $1.9 \mathrm{~g} \mathrm{~cm}^{-3}$ to $1.87 \mathrm{~g} \mathrm{~cm}^{-3}$. A pellet density of $1.87 \mathrm{~g} \mathrm{~cm}^{-3}$ could be composed of $70 \% \beta-$ $H M X$ and $30 \% \alpha-H M X$. These predictions were made assuming the radial expansion to be significantly smaller than the axial displacement. Figure 9 also shows the predicted axial force with a prescribed HMX pellet displacement between 56 and 60 minutes of $0.175 \mathrm{~mm}$, representing $100 \%$ conversion of $\beta-H M X$ to $\delta-H M X\left(1.9 \mathrm{~g} \mathrm{~cm}^{-3}\right.$ to $\left.1.8 \mathrm{~g} \mathrm{~cm}^{-3}\right)$.

We have attempted to monitor the HMX phase using Raman spectroscopy. The $\beta$ and $\delta$ polymorphs have distinctive features near $400 \mathrm{~cm}^{-1}$. We adapted the top piston of the hot cell configuration to seal a sapphire window at the surface and used an optical fiber to deliver the pulsed laser light to the pellet surface and to return scattered Raman radiation to a spectrometer. Unfortunately, these experiments have not been successful, due to a large fluorescence background generated at the desired wavelengths. We are continuing to make improvements in the optical design and hope eventually to monitor the phase transition of $\mathrm{HMX}$ spectroscopically in real time. 
$H M X$ heated in the constant-load experiment responded quite differently to HMX heated in the constant-volume configuration. We expected that a major difference in reactivity may arise from the lower (constant) pressure of the constant-load experiment. Generally, reaction rates are accelerated at high pressure, and pressures one order of magnitude higher were obtained in the constant-volume configuration. In our experiments, however, we observed the faster reactivity in the lower-pressure experiments. Our data showed that HMX heated in a constantload configuration (lower pressure) transitioned completely to the $\delta$-polymorph. The subsequent rapid reactions indicated that decomposition rates of HMX may be dependent on its crystal state. The violence of the cookoff reactions we observed was probably aided by the decreasing density (increasing porosity) of the HMX pellet as it pushed against the moveable piston. The burn dynamics of a more porous material may lead to a more rapid transition to thermal explosion.

\section{CONCLUSION}

The results of these tests showed that it is important to test EM in configurations representative of their use in weapon systems and components. For HMX we found that the ability to transition to a more reactive crystal phase is more important than reaction acceleration due to high-pressure chemistry. The specific state of the EM at the time of ignition was shown to have dramatic control on the violence and consequence of the cookoff event.

\section{ACKNOWLEDGEMENTS}

We express thanks to Steve Sheffield of LANL for sending us the HMX that had been sieved for narrow distributions of particle size.

\section{REFERENCES}

1. Hobbs, M. L., Schmitt, R. G., Renlund, A. M., "Analysis of Thermally-Degrading, Confined HMX," 1996 JANNAF Propulsion Systems Hazards Subcommittee Meeting, Monterey, CA (1996).

2. Renlund, A. M., Miller, J. C., Hobbs, M. L.. Baer, T. A., and Baer, M. R., "Experimental and Analytical Characterization of Thermally Degraded Energetic Materials", Proceedings of the 1995 JANNAF Propuision Systems Hazards Subcommittee Meeting. Huntsville, AL, 1995.

3. Karpowicz, R. J., and Brill, T. B., "The $\beta-\delta$ Transformation of HMX: Its Thermal Analysis and Relationship to Propellants" AIAA Journal, 20, 1586 (1982).

4. Gibbs, T. R., Popolato, A., LASL Explosive Property Data, University of California Press, Berkeley, CA (1980).

5. Hobbs, M. L., Baer, M. R., and Gross, R. J.. "A Constitutive Mechanical Model for Energetic Materials," Twentieth International Pyrotechnics Seminar, IIT Research Institute, Colorado Springs, Colorado, 423 (1994).

6. Hobbs. M. L., Schmitt, R. G., and Renlund. A. M., "Analysis of Thermally-Degrading, Confined HMX." 1996 JANNAF Propulsion Systems Hazards Succommittee Meeting, Naval Postgraduate Schcol. Monterey. CA (1996). 